University of Arkansas, Fayetteville

ScholarWorks@UARK

Education Reform Faculty and Graduate

Students Publications

Education Reform

8-16-2021

\title{
Understanding how COVID-19 has Changed Teachers' Chances of Remaining in the Classroom
}

\author{
Gema Zamarro \\ University of Arkansas, Fayetteville, gzamarro@uark.edu \\ Andrew Camp \\ University of Arkansas, Fayetteville \\ Dillon Fuchsman \\ Saint Louis University \\ Josh B. McGee \\ University of Arkansas, Fayetteville, jbm04@uark.edu
}

Follow this and additional works at: https://scholarworks.uark.edu/edrepub

Part of the Educational Assessment, Evaluation, and Research Commons, Educational Leadership Commons, and the Other Educational Administration and Supervision Commons

\section{Citation}

Zamarro, G., Camp, A., Fuchsman, D., \& McGee, J. B. (2021). Understanding how COVID-19 has Changed Teachers' Chances of Remaining in the Classroom. Education Reform Faculty and Graduate Students Publications. Retrieved from https://scholarworks.uark.edu/edrepub/127

This Article is brought to you for free and open access by the Education Reform at ScholarWorks@UARK. It has been accepted for inclusion in Education Reform Faculty and Graduate Students Publications by an authorized administrator of ScholarWorks@UARK. For more information, please contact scholar@uark.edu. 


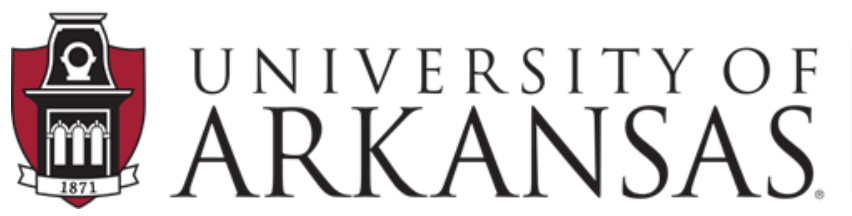

College of Education \& Health Professions Education Reform

\author{
Research Brief
}

\title{
Understanding how COVID-19 has Changed Teachers' Chances of Remaining in the Classroom
}

Gema Zamarro, Andrew Camp, Dillon Fuchsman, and Josh McGee

Last Revised 8-16-2021

EDRE Research Brief 2021-01 


\title{
Understanding how COVID-19 has Changed Teachers' Chances of Remaining in the Classroom
}

\author{
Gema Zamarro*, Andrew Camp*, Dillon Fuchsman**, and Josh McGee* \\ *University of Arkansas \\ **Saint Louis University
}

August 2021

The 2020-2021 academic year was a year like no other. After nationwide school closures during the spring of 2020, schools reopened in the fall of 2020 using combinations of in-person, hybrid, and remote learning models. Teachers had to adapt to unexpected conditions, teaching in unprecedented ways, using synchronous and asynchronous instruction, while also being challenged to establish connections with students, families, and colleagues. Health concerns added to the mix as some teachers went back to inperson education during the height of the pandemic. As a result, teachers' levels of stress and burnout have been high throughout these unusual pandemic times (Diliberti et al., 2021), raising concerns about a potential increase in teacher turnover and future teacher shortages (Goldberg, 2021; Lavery, 2020).

A RAND survey, fielded in early January 2021, found that nearly one-quarter of teachers indicated a desire to leave their jobs at the end of the school year (Steiner \& Woo, 2021), compared with an average national turnover rate of $16 \%$ pre-pandemic (NCES, 2019). However, so far, teacher attrition rates have not increased (Barnum, 2021). But, as the pandemic continues and the delta variant presents new challenges for the 2021-2022 academic year, the added stress could result in more teachers leaving as the economy recovers and they have more employment options.

Teacher turnover is often bad for students (Hanushek et al., 2016), and a teacher shortage might be particularly disruptive in certain subjects or jurisdictions that are already strained (Goldhaber, 2021). In addition, higher levels of job dissatisfaction and intentions to leave could affect teacher effectiveness and could harm student academic progress even if teachers do not leave. It is, therefore, important to get a better understanding of the factors that explain the increase in teachers' considerations to leave so that we might find ways to better support teachers during these challenging times. This research brief summarizes new survey data that provides some insight into these issues. 


\section{Data}

We included questions on a 15-minute survey administered to the nationally representative RAND American Teacher Panel (ATP) ${ }^{1}$ from March 22 to March 31, 2021. Respondents answered questions about their current jobs, job preferences, their colleagues, and COVID-19 risks during the 2020-21 school year. Additional questions inquired about respondents' vaccination status and teaching mode (in-person, online, etc.). Our sample contained 1,045 teachers.

Following the national composition of the teaching labor force, most teachers in our sample $(73.2 \%)$ are female and $84 \%$ are white. $29.3 \%$ of teachers in our sample teach in a city, $39 \%$ teach in the suburbs, while $32 \%$ teach in a town or rural area. Using these data, we identify teachers who are approaching retirement age as those who are 55 years old or older $(\mathrm{N}=193 ; 18.5 \%) .309$ teachers in our sample (29.8\%) reported teaching fully remote to most of their students for the majority of the school year, 509 (49\%) of teachers reported they taught in a hybrid model, while $220(21.2 \%)$ reported teaching fully in person. Finally, $71 \%$ of teachers in our sample reported they had to switch instructional models at least once during the 2020-2021 school year, and the average teacher switched models twice.

Additionally, we use responses to a pre-pandemic survey of 5,464 teachers ${ }^{2}$. Survey administration took place from February 10 to March 16, 2020 and focused on teachers' retirement knowledge and preferences. Several questions on the 2020 survey were repeated on the 2021 survey, allowing us to see how teachers' attitudes may have changed through the pandemic. We use survey weights included with the ATP to maintain a nationally representative sample of teachers.

\section{During the pandemic, teachers became less certain that they would work a full career in the classroom.}

In March 2020, 74.2\% of teachers reported that they expected to work as a teacher until retirement, while 9.3\% said they did not expect to, and 16.5\% did not know. In contrast, in March 2021, 69\% of teachers reported they expected to work as a teacher until retirement, while $9.5 \%$ reported they did not expect to and $21.5 \%$ said they didn't know.

Teachers' reported probability of leaving their current state or the profession within the next 5 years also increased from 24\% on average in March of 2020 to 30\% in March 2021. This change was due to a reduction in the percentage of teachers reporting a zero probability of leaving their current state or the profession within the next 5 years and a corresponding increase in the percentage reporting a $50 \%$ chance and a $100 \%$ chance. We observed similar reported probabilities regardless of the mode of instruction.

\footnotetext{
${ }^{1}$ https://www.rand.org/education-and-labor/projects/aep/about.html. RAND American Educator Panels, American Teacher Panel, 2021 ATP Module on Finances, Retirement, and Job Preferences, UAR0421T, RAND Corporation, Santa Monica, CA, April, 2021.

2 RAND American Educator Panels, American Teacher Panel, 2020 ATP Survey on Finances, Retirement, and Job Preferences, UAR0120T, RAND Corporation, Santa Monica, CA, April, 2020.
} 


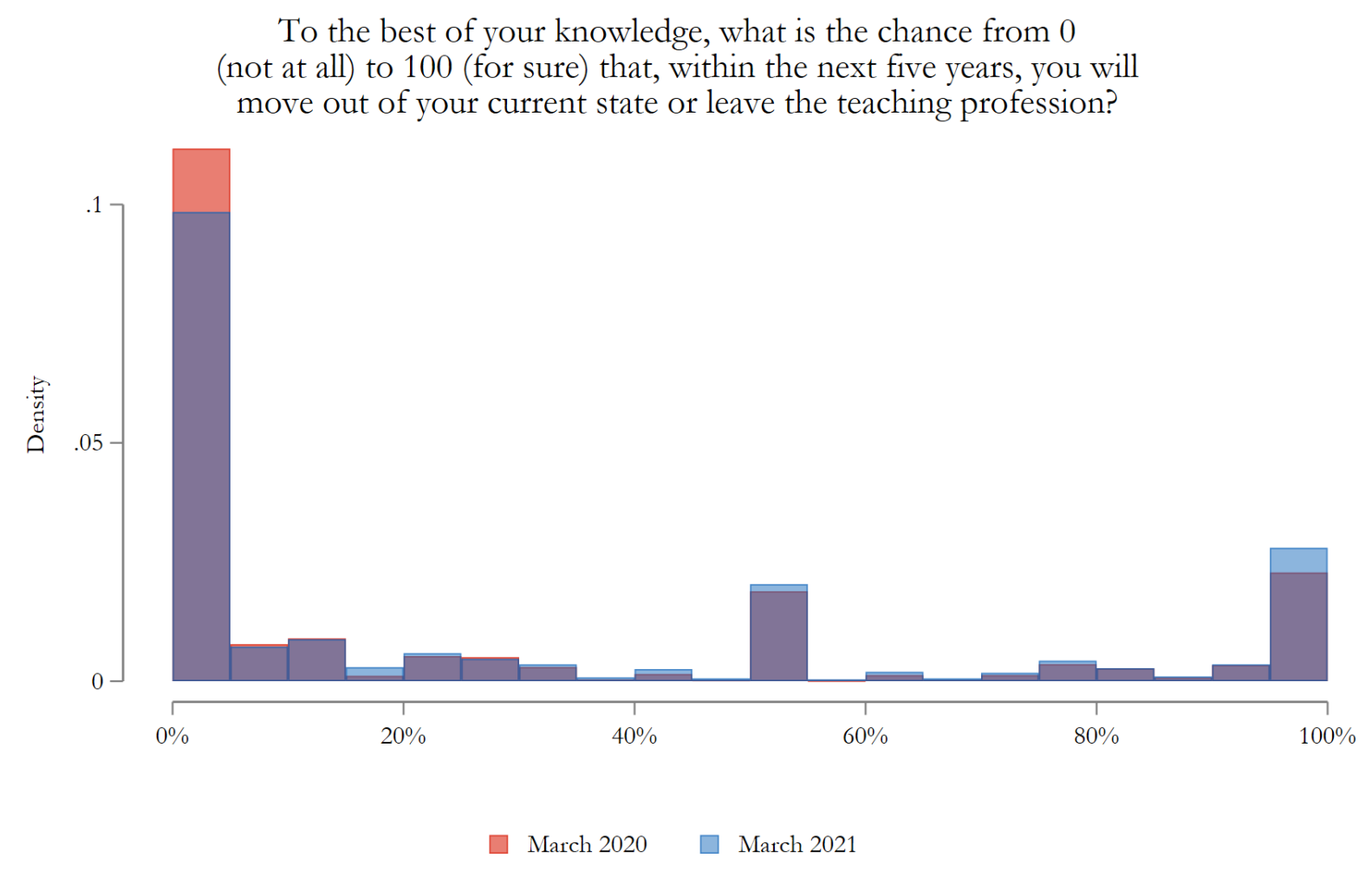

\section{A high proportion of teachers considered leaving or retiring during the 2020-2021 academic year.}

In March 2021, 42\% of teachers declared they have considered leaving or retiring from their current position during the last year. Of these, 23\% declared it was because of the COVID-19 pandemic while $19 \%$ declared it was for other reasons.

Although the proportion of teachers that considered leaving or retiring during the 2020-2021 school year was similar across different experience levels, those approaching retirement (55 years old or older) considered leaving at higher rates. $34 \%$ of teachers 55 and older declared they considered leaving or retiring because of COVID-19 as compared to $23 \%$ for all respondents. 
Did you consider leaving or retiring from your current position as a teacher in the last year?

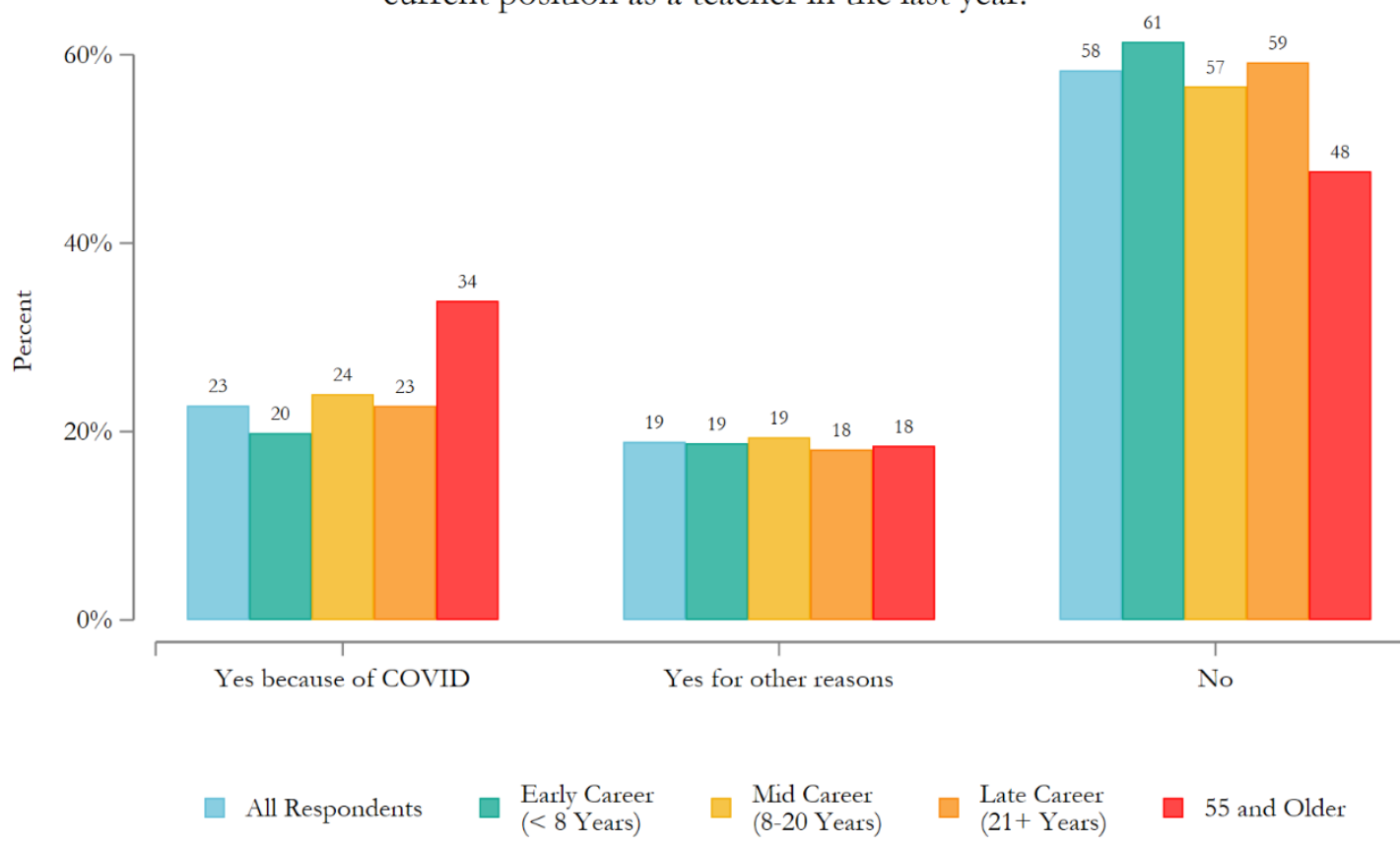

In-person teachers were less likely to report that they considered leaving or retiring because of COVID $(15 \%)$ than those teaching fully remote $(23 \%)$ or hybrid $(26 \%)$. However, a higher proportion of inperson teachers $(27 \%)$ reported having considered leaving or retiring for other reasons than fully remote or hybrid teachers (14\% and $18 \%$, respectively).

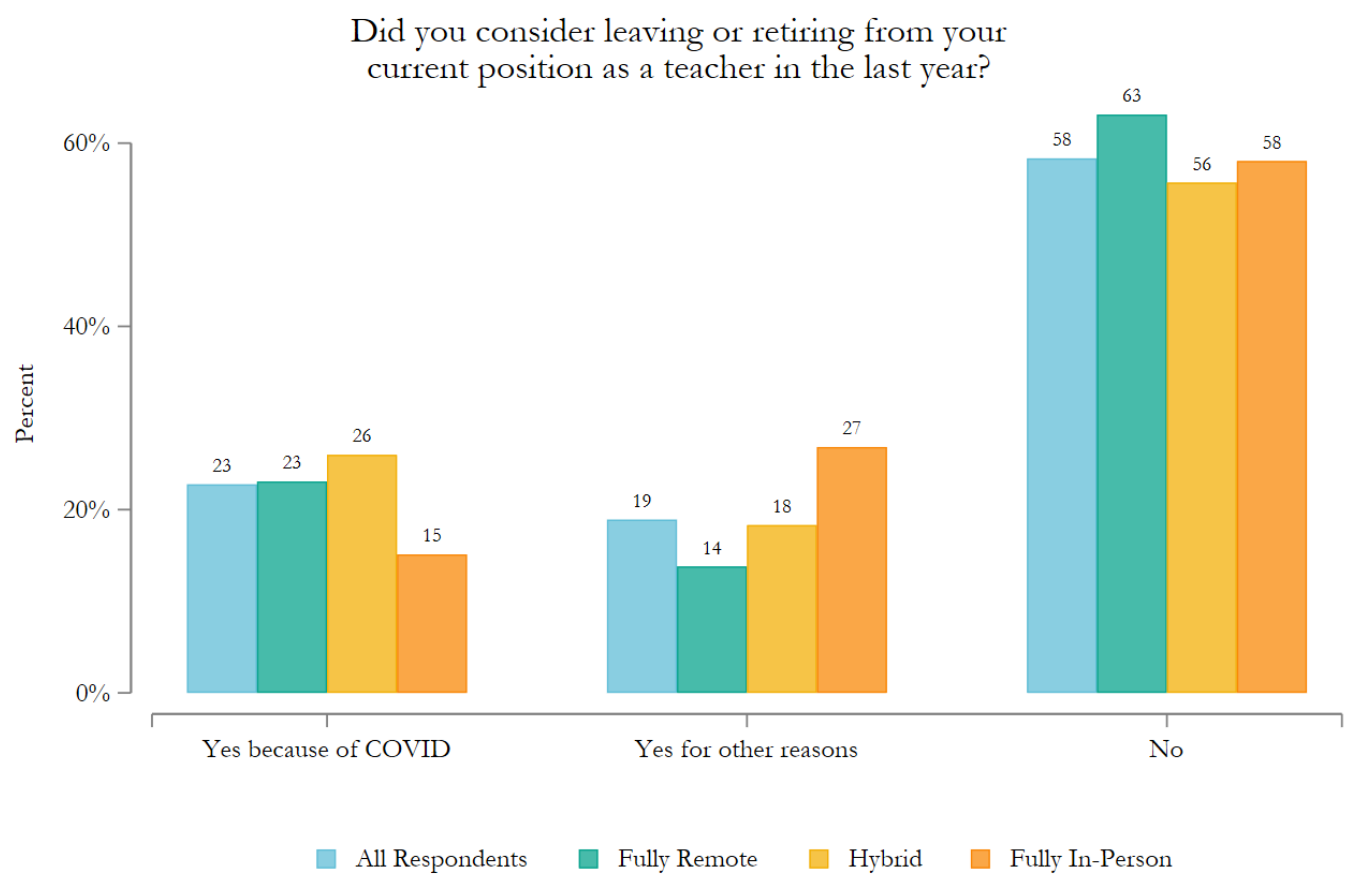




\section{Approaching retirement age (being 55 or older), having to change instruction modes, and health concerns appear to be important predictors of the probability of considering leaving or retiring from teaching.}

We use statistical logit models to study factors associated with the probability of teachers considering leaving or retiring from the profession in the last year. We also use multinomial logit models to study factors associated with the separate probabilities of considering leaving or retiring because of COVID, for other reasons, or not considering leaving at all. The full set of results can be found in Appendix Table 1 .

Those teachers approaching retirement, age 55 and older, were 11 percentage points more likely to say they have considered leaving or retiring during the past year because of COVID, as compared to teachers younger than 35. Importantly, teachers nearing the retirement age were not more likely than other teachers to report having considered leaving or retiring for reasons other than COVID.

Having to change instruction mode at least once during the year is associated with a 13 percentage point higher probability of having considered leaving or retiring. Most teachers in our sample declared they had to switch instructional models at least once during the 2020-2021 school year, with teachers doing so twice on average.

Finally, we measure teachers' health concerns using teachers' reported probability of getting COVID-19 in the next 3 months and their reported probability of being hospitalized or dying because of COVID. Compared to teachers who report a zero percent chance of getting COVID-19, those who think they have a 50\% chance are 10 percentage points more likely to have considered leaving or retiring. We observe a similar effect for teachers' reported probability of being hospitalized or dying because of COVID if infected.

\section{Teachers report that more of their colleagues have considered leaving than have left their teaching jobs.}

We asked teachers to report, to the best of their knowledge, the number of their school colleagues that have considered leaving or retiring because of the COVID-19 pandemic, and then we asked how many of those colleagues left or retired. On average, teachers reported they knew 6 colleagues at their school that considered leaving or retiring because of COVID, with the median teacher reporting 3 . Among those that reported knowing at least one colleague who has thought about leaving or retiring because of COVID, on average, teachers reported they knew about 3 who left with the median teacher reporting 2. On average, teachers reported that around $40 \%$ of their colleagues that considered leaving because of COVID ended up leaving.

Ten percent of the teachers in our sample reported a higher number of colleagues leaving than the number of colleagues they knew considered it. On average, they reported 2 more colleagues leaving than the number of colleagues that considered it. This could reflect some unexpected departures for some teachers. 


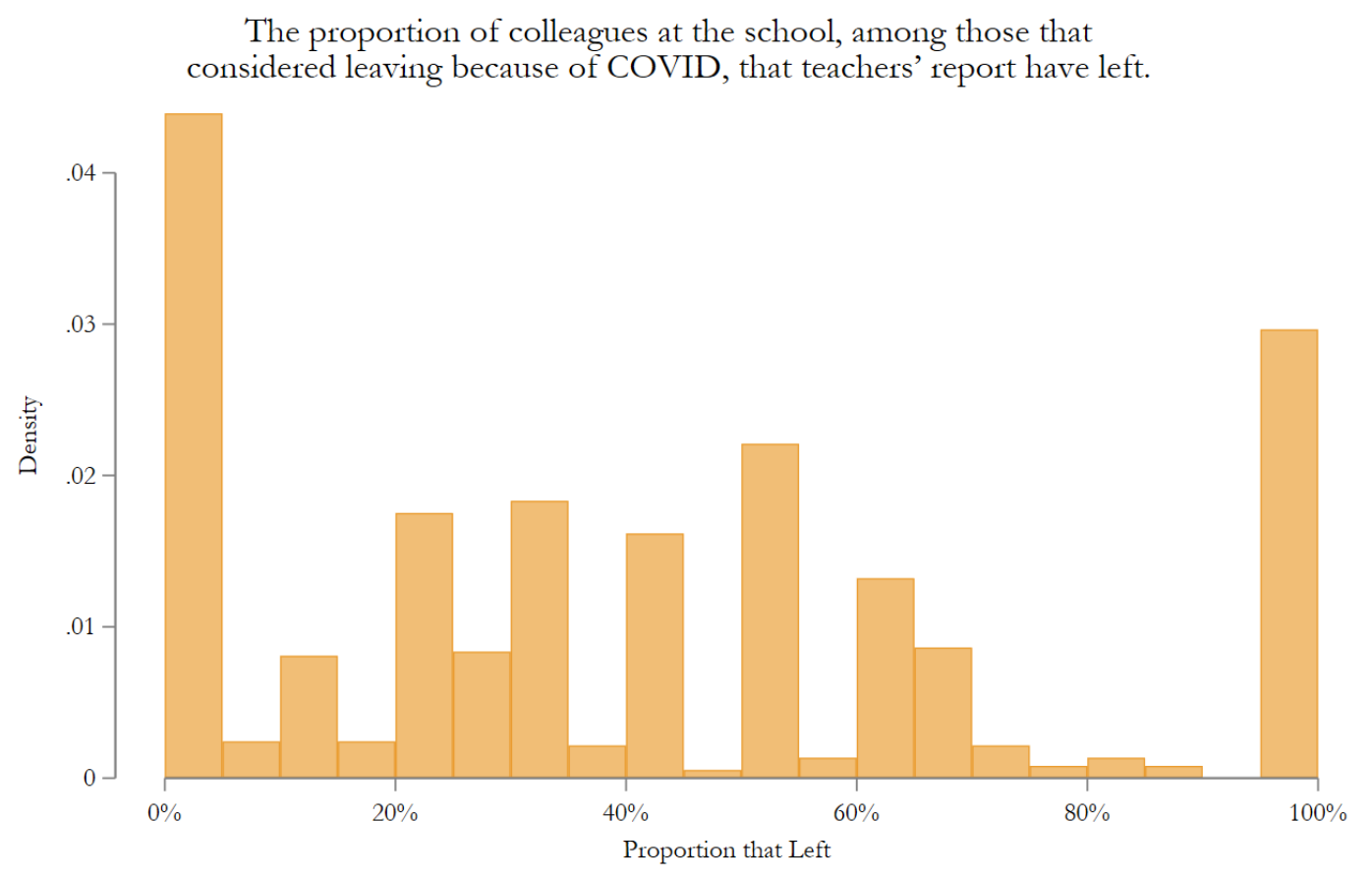

\section{Discussion}

The 2020-2021 academic year was a trying year for teachers and, as a result, teachers reported a higher probability that they will leave the profession than they did before the pandemic. In March 2020, 74.2\% of teachers reported that they expected to work as a teacher until retirement. In March 2021, only 69\% of teachers declared they intended to continue to be a teacher until they retire, and $42 \%$ said they considered leaving or retiring during the last year.

A larger proportion of those approaching retirement age (55 years old and older) reported having considered leaving or retiring because of COVID during the past year, which could be problematic for schools as they might lose their more experienced teachers.

Most teachers had to change instructional mode at least once and many experienced multiple disruptions during the year. Having to change instructional modes was associated with an increased probability of considering leaving or retiring. COVID health concerns were also an important factor associated with an increased probability of considering leaving. Addressing health concerns while trying to minimize school disruptions and changes in teaching mode could help retain teachers.

Teachers reported that, among their colleagues, considering leaving was more prevalent than doing so. However, as the pandemic continues and the delta variant presents new challenges for the 2021-2022 academic year, there is an ongoing risk that teacher turnover might increase. Even small rates of teacher turnover could be problematic if concentrated in areas with teacher shortages (e.g., rural areas or teachers in certain fields like Math and Sciences). Finally, higher levels of job dissatisfaction could affect teacher effectiveness and could harm student academic progress even if teachers decide not to leave.

Acknowledgment: We thank the Walton Family Foundation and the Equable Institute for financial support.

Media: Gema Zamarro (gzamarro@uark.edu) is available for comment on this study's findings. 


\section{Appendix}

Table 1: Factors Related to the Probability of Considering Leaving or Retiring in the Last Year

\begin{tabular}{|c|c|c|c|c|}
\hline & \multirow[t]{2}{*}{$\begin{array}{l}\text { Considered } \\
\text { Leaving }\end{array}$} & \multicolumn{2}{|c|}{ Considered Leaving } & \multirow{2}{*}{$\begin{array}{l}\text { Did not Consider } \\
\text { Leaving } \\
\text { (4) }\end{array}$} \\
\hline & & $\begin{array}{c}\text { Because of } \\
\text { COVID } \\
(2)\end{array}$ & $\begin{array}{c}\text { For other } \\
\text { reasons } \\
\text { (3) }\end{array}$ & \\
\hline \multirow[t]{2}{*}{ Female } & 0.049 & 0.038 & 0.006 & -0.044 \\
\hline & $(0.036)$ & $(0.030)$ & $(0.029)$ & $(0.036)$ \\
\hline \multirow[t]{2}{*}{ Non White } & -0.010 & 0.047 & -0.061 & 0.014 \\
\hline & $(0.046)$ & $(0.037)$ & $(0.039)$ & $(0.047)$ \\
\hline \multirow[t]{2}{*}{ Fully Remote } & -0.043 & 0.013 & -0.042 & 0.029 \\
\hline & $(0.054)$ & $(0.048)$ & $(0.041)$ & $(0.055)$ \\
\hline \multirow[t]{2}{*}{ Hybrid } & -0.007 & 0.051 & -0.044 & -0.008 \\
\hline & $(0.043)$ & $(0.038)$ & $(0.031)$ & $(0.043)$ \\
\hline \multirow[t]{2}{*}{ Age 35-44 } & -0.040 & 0.003 & -0.042 & 0.039 \\
\hline & $(0.042)$ & $(0.036)$ & $(0.033)$ & $(0.042)$ \\
\hline \multirow[t]{2}{*}{ Age 45-54 } & -0.026 & -0.010 & -0.015 & 0.025 \\
\hline & $(0.043)$ & $(0.037)$ & $(0.032)$ & $(0.042)$ \\
\hline \multirow[t]{2}{*}{ Age 55 and older } & $0.090 *$ & $0.108 * * *$ & -0.020 & $-0.088 *$ \\
\hline & $(0.050)$ & $(0.040)$ & (0.039) & $(0.050)$ \\
\hline \multirow[t]{2}{*}{ Elementary grades } & $-0.058 *$ & $-0.057 * *$ & 0.001 & 0.056 \\
\hline & $(0.035)$ & $(0.029)$ & $(0.028)$ & $(0.035)$ \\
\hline \multirow[t]{2}{*}{ Middle grades } & -0.036 & $-0.051 *$ & 0.014 & 0.037 \\
\hline & $(0.036)$ & $(0.030)$ & $(0.028)$ & $(0.036)$ \\
\hline \multirow[t]{2}{*}{ Vaccinated } & -0.025 & 0.015 & -0.035 & 0.020 \\
\hline & $(0.037)$ & $(0.032)$ & $(0.028)$ & $(0.037)$ \\
\hline \multirow[t]{2}{*}{ Had to Change Instruction Mode } & $0.127^{* * *}$ & $0.055^{*}$ & $0.076 * *$ & $-0.131 * * *$ \\
\hline & $(0.036)$ & $(0.031)$ & $(0.030)$ & $(0.036)$ \\
\hline \multirow[t]{2}{*}{ Suburbs } & -0.047 & -0.016 & -0.030 & 0.047 \\
\hline & $(0.039)$ & $(0.032)$ & $(0.032)$ & $(0.039)$ \\
\hline \multirow[t]{2}{*}{ Town/Rural } & -0.006 & -0.021 & 0.011 & 0.010 \\
\hline & $(0.043)$ & $(0.035)$ & $(0.033)$ & $(0.042)$ \\
\hline \multirow[t]{2}{*}{ Perceived Probability of Covid } & $0.002 * *$ & $0.001^{*}$ & 0.001 & $-0.002 * *$ \\
\hline & $(0.001)$ & $(0.001)$ & $(0.001)$ & $(0.001)$ \\
\hline \multirow[t]{2}{*}{ Perceived Prob. Hospital/Death } & $0.002 * *$ & $0.002 * * *$ & -0.001 & $-0.001^{*}$ \\
\hline & $(0.001)$ & $(0.001)$ & $(0.001)$ & $(0.001)$ \\
\hline Observations & 1,016 & 1,020 & 1,020 & 1,020 \\
\hline
\end{tabular}

Note: State fixed effects included. Standard errors in parentheses. $* * * \mathrm{p}<0.01, * * \mathrm{p}<0.05,{ }^{*} \mathrm{p}<0.1$ 


\section{References}

Barnum, M. (2021, April 6). Despite pandemic, there's little evidence of rising teacher turnover-Yet. Chalkbeat. https://www.chalkbeat.org/2021/4/6/22368846/teacher-turnover-quitting-pandemicdata-economy

Diliberti, M. K., Schwartz, H. L., \& Grant, D. (2021). Stress Topped the Reasons Why Public School Teachers Quit, Even Before COVID-19. RAND Corporation. https://doi.org/10.7249/RRA1121-2

Goldberg, E. (2021, April 7). As Pandemic Upends Teaching, Fewer Students Want to Pursue It. The New York Times. https://www.nytimes.com/2021/03/27/us/covid-school-teaching.html

Goldhaber, D. (2021, May 18). Analysis: COVID-19 Raised Fears of Teacher Shortages. But the Situation Varies from State to State, School to School \& Subject to Subject. The 74 Million. https://www.the74million.org/article/analysis-covid-19-raised-fears-of-teacher-shortages-but-thesituation-varies-from-state-to-state-school-to-school-subject-to-subject/

Hanushek, E. A., Rivkin, S.G., \& Schiman, J. C. (2016). Dynamic Effects of Teacher Turnover on the Quality of Instruction, Economics of Education Review, 55, 132-148.

Lavery, L. (2020, December 19). The pandemic is causing teachers to flee the profession. Salon. https://www.salon.com/2020/12/19/the-pandemic-is-causing-teachers-to-flee-the-profession/

NCES. (2019). Table 210.30. Mobility of public elementary and secondary teachers, by selected teacher and school characteristics: Selected years, 1987-88 through 2012-13. In Digest of Education Statistics. https://nces.ed.gov/programs/digest/d19/tables/dt19_210.30.asp

Steiner, E. D., \& Woo, A. (2021). Job-Related Stress Threatens the Teacher Supply: Key Findings from the 2021 State of the U.S. Teacher Survey. RAND Corporation. https://doi.org/10.7249/RRA1108-1 